\title{
A study of supercooling phenomenon and freezing probability of water inside horizontal cylinders
}

\author{
SIH-LI CHEN and TZONG-SHING LEE \\ Department of Mechanical Engineering, National Taiwan University, Taipei, Taiwan 10764, \\ Republic of China
}

(Received 24 December 1996 and in final form 6 May 1997)

\begin{abstract}
This paper investigates the supercooling phenomenon and the freezing probability of water inside horizontal cylinders during a cooling process of thermal storage. The effect of such factors as cooling rate, inside diameter of cylinders and mass of different nucleation agents is experimentally examined. By measuring the time variations of temperature profiles at various locations inside the test cylinder and the photography observation at the time of nucleation, the supercooling period of water and the extent of dendritic ice growth is presented. The probability curves of initial appearance of dendritic ice as a function of various factors are characterized. Besides, a simple model to predict the critical cooling rate for dendritic ice blockage and supercooling period for container water is proposed. By incorporating the experimental results and the theoretical predictions, a correlation of supercooling period for water inside horizontal cylinders has also been developed. (C) 1997 Elsevier Science Ltd.
\end{abstract}

\section{INTRODUCTION}

The cool storage air-conditioning system is an important concept of many energy conservation programs in industry and in commercial applications. Water is widely used as the phase change material (PCM) for cool storage because of the advantages of water, such as : high value in latent heat, stable chemical property, low cost and easy acquisition, no environmental pollution concern ancl compatibility with the material of air-conditioning equipment. However, there are a few disadvantages with the use of water as PCM. One of the most serious problems is the supercooling phenomenon occurring in the solidification of water during the cooling process of thermal storage.

As a quantity of water is cooled inside an enclosed container, freezing does not occur at its freezing point $\left(0^{\circ} \mathrm{C}\right)$. Instead it is normally cooled to below $0^{\circ} \mathrm{C}$ before ice nucleation happens. Water below the freezing point is called supercooled and is a state of metastable. The metastable state will be ended when ice nucleation occurs and the thin plate-like crystals of dendritic ice grows into the supercooled region of water. During the dendritic ice growth process, the latent heat released from dendritic ice will be consumed by supercocled water. At the end of the growth process, the temperature of water will then return to its freezing point $\left(0^{\circ} \mathrm{C}\right)$. If a metastable state exists and remains during the thermal storage process, cool energy can only be stored in the form of sensible energy. To store the cool energy in the form of latent heat, the coolant entrance temperature of the storage tank must be lower than the water nucleation tem- perature. To achieve this goal, it is necessary to lower the evaporation temperature of the chiller unit. This action tends to cause a decline in the coefficient of performance (COP) of the chiller unit at the same time.

A number of researches have been conducted in the area of supercooling phenomenon and dendritic ice formation in an enclosed container. Gilpin [1, 2] studied the extent of dendritic ice growth into the supercooling water and determined the conditions under which blockage by dendritic ice was likely to occur in a pipe with no main flow. Chen et al. [3] used the numerical method to study transient natural convection in a horizontal pipe with a convective boundary condition. Both maximum density effect and supercooling phenomena were considered. The effect of convective flow on the degree of supercooling has been studied by Kashiwagi et al. [4]. They experimentally studied the flow and the heat transfer characteristics of pooled water with a supercooled region by using a real-time holographic interferometry technique. Saito et al. [5] conducted experiments on the supercooling phenomenon of pure water inside an enclosed cylinder by using round plates of five different characteristics of surface roughness as the heat transfer interface. The same work was further improved by Saito and Okawa [6]. Arnold [7] investigated the nucleation phenomenon of pure water contained inside spherical capsules and indicated that the nucleation temperature of water inside the container is affected by both the cooling rate and the addition of a nucleation agent.

In relation to the energy efficiency of cool storage 


\section{NOMENCLATURE}

$\begin{array}{ll}g & \text { gravity acceleration }\left[\mathrm{m} \mathrm{s}^{-2}\right] \\ k & \text { thermal conductivity }\left[\mathrm{W} \mathrm{m}^{-10} \mathrm{C}^{-1}\right] \\ p & \text { coordinate tangent to cylinder wall } \\ q & \text { coordinate perpendicular to cylinder } \\ & \text { wall } \\ t & \text { time } \\ (\Delta t)_{\mathrm{s}} & \text { supercooling period } \\ u & \text { velocity in boundary layer } \\ V_{\mathrm{c}} & \text { core velocity } \\ x & \text { vertical coordinate } \\ y & \text { horizontal coordinate } \\ C_{\mathrm{p}} & \text { specific heat of water } \\ C_{\mathrm{T}} & \text { constant, } 2.62\left(\alpha^{3} g|\beta| / v\right)^{1 / 4} \\ D & \text { diameter of cylinder [m] } \\ F & \text { non-dimensional similarity parameter } \\ G & \text { non-dimensional boundary-layer } \\ & \text { thickness } \\ H & \text { cooling rate, C/min } \\ H_{\mathrm{cri}} & \text { critical cooling rate, C/min } \\ J & \text { non-dimensional similarity parameter } \\ J_{\mathrm{CL}} & \text { non-dimensional center line } \\ & \text { temperature } \\ J^{\prime} & =\mathrm{d} J / \mathrm{d} \xi \\ J^{\prime \prime} & =\mathrm{d}^{2} J / \mathrm{d} \xi^{2} \\ P & \text { freezing probability } \\ P r & \text { Prandtl number } \\ R & \text { radius of cylinder [m] } \\ R a & \text { Rayleigh number }(g|\beta| / \alpha v) D^{3} \Delta T^{*} \\ & \end{array}$

$T$ temperature $\left[{ }^{\circ} \mathrm{C}\right]$

$T_{\mathrm{f}, \text { in }}$ inlet coolant temperature [ ${ }^{\circ} \mathrm{C}$ ]

$T_{\mathrm{i}} \quad$ initial water temperature $\left[{ }^{\circ} \mathrm{C}\right]$

$T_{\mathrm{CL}} \quad$ centerline temperture

$T_{\mathrm{n}} \quad$ nucleation temperature

$T_{\mathrm{w}} \quad$ wall temperature

$T_{\text {wi }} \quad$ initial wall temperature

$\Delta T^{*} \quad$ characteristic temperature difference

$U^{*} \quad$ characteristic velocity $\left[\mathrm{m} \mathrm{s}^{-1}\right]$.

$\begin{array}{ll}\text { Greek symbols } \\ \alpha & \text { thermal diffusivity }\left[\mathrm{m}^{2} \mathrm{~s}^{-1}\right] \\ \beta & \text { coefficient of thermal expansion }\left[{ }^{\circ} \mathrm{C}^{-1}\right] \\ \delta & \text { boundary-layer thickness } \\ \delta^{*} & \text { characteristic boundary-layer } \\ & \text { thickness } \\ \varepsilon & 1 /\left(G R a^{1 / 4}\right) \\ \eta & q / \delta \\ \theta & \text { angle measured from bottom of } \\ & \text { cylinder } \\ \nu & \text { kinematic viscosity }\left[\mathrm{m}^{2} \mathrm{~s}^{-1}\right] \\ \xi & \text { x/ } D \\ \rho & \text { water density } \\ \rho_{\mathrm{c}} & \text { water density in core flow } \\ \rho_{0} & \text { water density at } 0^{\circ} \mathrm{C} \\ \psi & \text { temperature difference, } T-T_{\mathrm{w}} \\ \psi_{\mathrm{C}} & \text { value of } \psi \text { in core flow } \\ \psi_{\mathrm{CL}} & \text { value of } \psi \text { in centerline. }\end{array}$

air-conditioning systems, it is important to minimize both the supercooling period and the degree of supercooling and consequently enhance the freezing probability. The main purpose of this work is to investigate, experimentally and theoretically, the effect of various factors on the supercooling phenomenon and the freezing probability of water inside horizontal cylinders. With a series of experimental work, a further understanding of the mechanism of supercooling phenomenon in the solidification process of water inside horizontal cylinders is established. Based on a quasi-steady approach on the water temperature variations inside the cylinder, we also develop a simple model to interpret the experimental measurements.

\section{EXPERIMENTAL APPARATUS AND PROCEDURE}

A schematic diagram of the experimental apparatus is shown in Fig. 1. It consists of a test section, a cooling section, an observing section, a measuring section and a filling section. The test section, as shown in Fig. 2 , contains a hollow copper cylinder with an inside diameter of $82.8 \mathrm{~mm}$, a thickness of $2.5 \mathrm{~mm}$, and a length of $147 \mathrm{~mm}$. Six cylinders with the inside diameters of $124.0,62.4,55.0,47.0,38.0$ and $32.0 \mathrm{~mm}$ were also tested. The distilled water enclosed in the test cell is confined by two parallel Plexiglas disks which clamped the copper cylinder to the outer jacket. Alco-

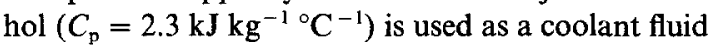
and kept at the test temperature setting in the constant-temperature bath. The coolant fluid is circulated through the annular gap (cooling chamber) between the copper cylinder and the outer cylindrical jacket of the test cell. The cooling section includes two constant-temperature baths and coolant pipe lines. One constant temperature is set at the required initial temperature, and the other is set at the test temperature. In order to minimize the heat gain from the environment, the coolant lines and the test section, except the Plexiglas disks, were well-insulated. The observing section included a camera and a lamp, which was used to visually observe and photograph the phenomenon in the process of dendritic ice growth. During the solidification process, excess pressure is induced if the water is confined in a fixed volume. In order to avoid the situation, the volumetric expansion of water is compensated by an overflow pipe of the filling section.

The measuring section includes eight T-type thermocouples, two flowmeters, one data recorder and one 486 personal computer. The coolant is circulated at constant flow rate of $41 \mathrm{~min}^{-1}$ (LPM) between the test cell and the constant temperature bath. The flow 


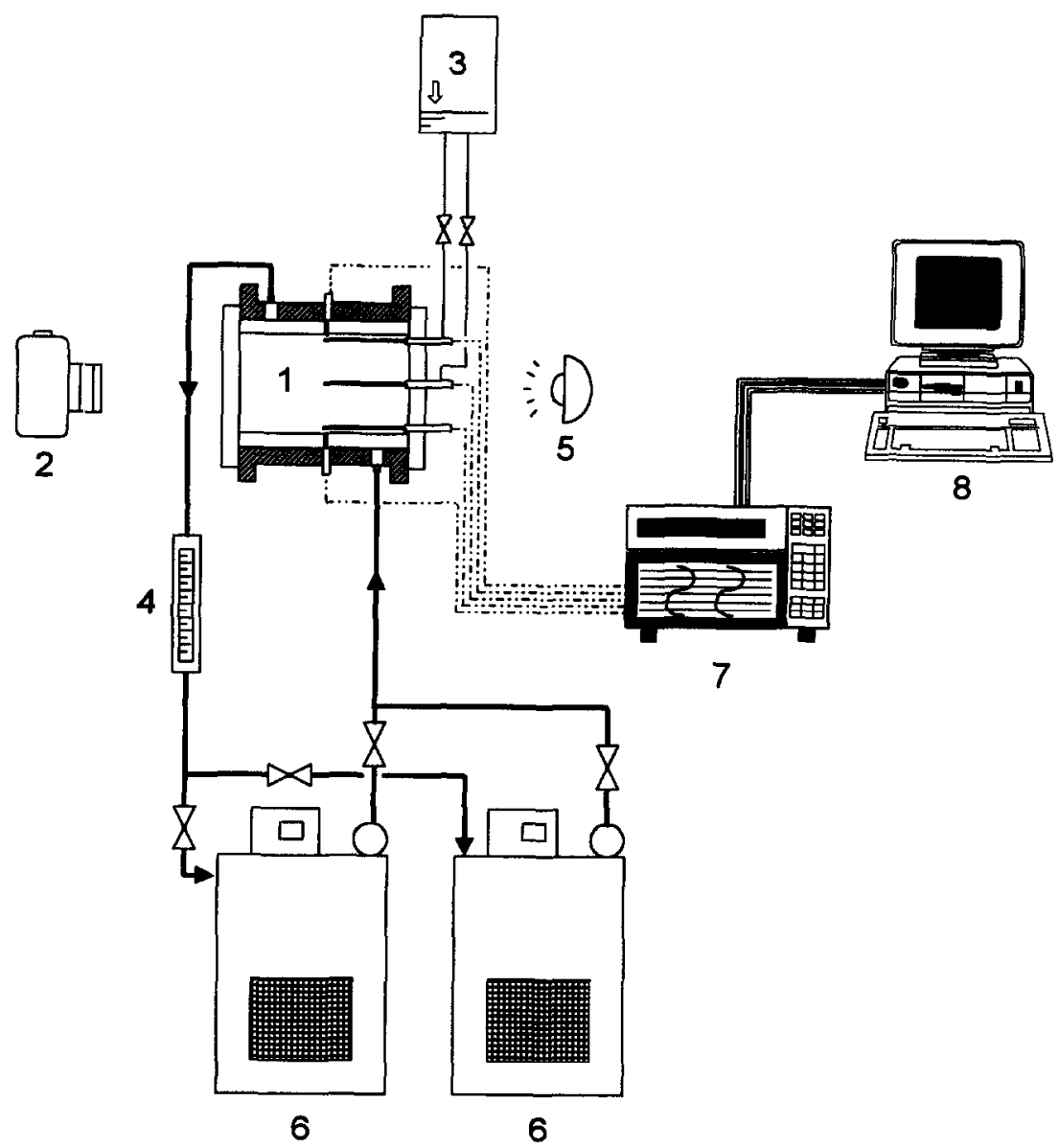

Fig. 1. Schernatic diagram of experimental apparatus: (1) test cell, (2) camera, (3) overflow tank, (4) flowmeter, (5) lamp, (6) constant temperature bath, (7) data recorder, (8) personal computer.

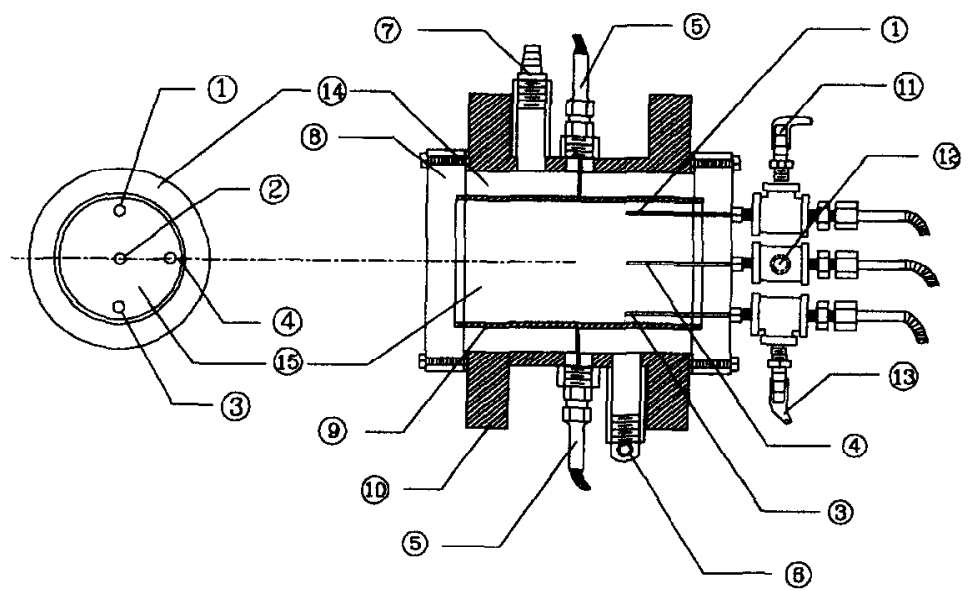

End view

\section{Side view}

Fig. 2. Details of the test section: (1) top thermocouple, (2) center line thermocouple, (3) bottom thermocouple, (4) side thermocouple, (5) wall temperature thermocouple, (6) coolant inlet, (7) coolant outlet, (8) Plexiglas disk, (9) hollow copper cylinder, (10) cylindrical jacket, (11) vent tube, (12) overflow tube or filling tube, (13) drain tube, (14) cooling chamber, (15) test cell.

rate is measured by a calibrated flowmeter with $\pm 2.5 \%$ accuracy. Four thermocouples are used to measure the temperature variation in the test cylinder and are buried at the top, the center, the bottom, and the inner side of the cylinder, respectively. For the measurement of the wall temperatures, two ther- 
Table 1. Summary of estimated uncertainties

\begin{tabular}{cc}
\hline \multicolumn{2}{c}{ Primary measurements } \\
\hline Parameter & Uncertainty \\
\hline Cylinder thickness & $0.4 \%$ \\
Length & $0.068 \%$ \\
Inside diameter & $0.263 \%$ \\
Temperature & $1.92 \%$ \\
Flow rate & $2.5 \%$ \\
Time & $0.42 \%$ \\
Derived quantities & \\
\hline Parameter & Uncertainty \\
\hline Cooling rate & $1.97 \%$ \\
Critical cooling rate & $2.42 \%$ \\
\hline
\end{tabular}

mocouples are cemented in small grooves on the outside surface of the copper cylinder, as shown in Fig. 2. Two thermocouples are mounted in the inlet and outlet coolant lines to measure the coolant temperature. These thermocouples are calibrated by using quartz thermometer and having a calibrated accuracy of $\pm 0.3^{\circ} \mathrm{C}$. The emfs of the thermocouples are read by a multi-channel recorder (HR2300 Hybrid Recorder, Yokogawa Electric Co., Ltd), all the data acquisition, reduction, evaluation and instrument control are aided by a 486 personal computer.

Prior to each experiment, the distilled water contained in the overflow tank is boiled for $30 \mathrm{~min}$ by using an electrical resistance heater for the purpose of degasification. After cooling at room temperature for half a day, the cooled distilled water is then carefully siphoned into the test cell through the filling tube. The coolant from a constant-temperature bath, which is preset at the desired initial temperature, is then circulated through the cooling chamber until the distilled water and the coolant attain steady and uniform state. The flow rate of the coolant is kept at a constant flow rate of 4 LPM.

After a steady and uniform temperature is attained within the test cell, the experiment is started by suddenly circulating the coolant continuously from another constant-temperature bath, which is preset at the desired test temperature, to the test section. At the same time, all the temperature variations start to measure and record at a time interval of $3 \mathrm{~s}$, and the solidification process is visualized and recorded photographically. The experiment is terminated after the ice state reaches the same temperature as the coolant, which takes about 2-5 $\mathrm{h}$ depending on the experimental conditions. Uncertainties of the primary measurements and the derived quantities, following the uncertainty analysis proposed by Moffat [8], are tabulated in Table 1.

\section{MATHEMATICAL MODEL}

In our work, an integral method similar to that proposed by Gilpin [1] is adopted to evaluate the

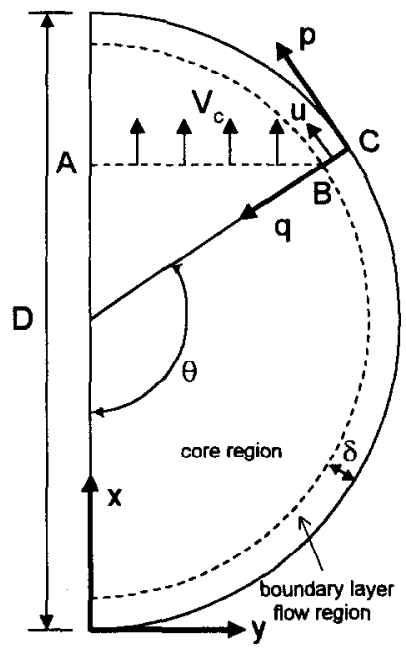

Fig. 3. Coordinates used in quasi-steady model.

temperature distributions inside the horizontal cylinder. The mathematical model is described below. Assuming that a quasi-steady state exists, the temperature variations of water in the cylinder may bc written as

$$
T(x, y, t)=\psi(x, y)+T_{\text {wall }}(t) .
$$

The wall temperature variation is

$$
T_{\text {wall }}(t)=T_{\mathrm{wi}}-H t
$$

The quasi-steady assumption can only be strictly valid if fluid properties are not temperature dependent. In the region of supercooled temperature considered in our experiments $\left(0--9^{\circ} \mathrm{C}\right)$ this assumption can be true.

The control volume can be divided into a core region and a boundary layer flow region, as shown in Fig. 3. The velocity, $u$, in the boundary layer is assumed to be parallel to the local tangent of the wall and confined to a small thickness, $\delta$. The velocity in the core, $V_{c}$, is assumed to be in the vertical, $x$, direction and to be independent of the $y$ position. Thus an integral equation of continuity can be obtained by integrating along the line $\mathrm{A}-\mathrm{B}-\mathrm{C}$ in $\mathrm{Fig}$. 3. This gives

$$
(R-\delta) \sin \theta V_{\mathrm{c}}+\int_{0}^{\delta} u \mathrm{~d} q=0
$$

where $R$ is the radius of the cylinder and $q$ is the coordinate perpendicular to cylinder wall.

The integrated momentum equation in the boundary layer is

$$
\frac{\partial}{\partial p} \int_{0}^{\delta} u^{2} \mathrm{~d} q=g \sin \theta \int_{0}^{\delta}\left(\rho_{\mathrm{c}}-\rho\right) \mathrm{d} q-\left.v\left(\frac{\partial u}{\partial q}\right)\right|_{q=0}
$$

where $p$ is the coordinate perpendicular to cylinder wall, $\rho$ is the density of water, $\rho_{\mathrm{c}}$ is the density of water 
in core flow region, $\boldsymbol{g}$ is gravity acceleration, and $v$ is the kinematic viscosity of water.

From the energy balance in the core region, the cooling rate $H$ can be obtained by

$$
H=V_{\mathrm{c}} \frac{\mathrm{d} \psi_{\mathrm{c}}}{\mathrm{d} x}
$$

where $\psi_{\mathrm{c}}$ is the value of $\psi$ in the core flow and is assumed to be a function of $x$ only. Then an energy balance in the boundary layer is obtained as

$$
\frac{\partial}{\partial p}\left(\int_{0}^{\delta} u \psi \mathrm{d} q\right)-\psi_{\mathrm{c}} \frac{\partial}{\partial p}\left(\int_{0}^{\delta} u \mathrm{~d} q\right)-H \delta=-\left.\alpha \frac{\partial \psi}{\partial q}\right|_{q=0}
$$

The equations (3)-(6) can be normalized by using the following characteristic parameters as

$$
\begin{aligned}
U^{*} & =\frac{\alpha}{D} R_{\alpha}^{1 / 2} \\
\delta^{*} & =D R_{\alpha}^{-1 / 4}
\end{aligned}
$$

and

$$
\Delta T^{*}=\frac{D^{2} H}{\alpha} R_{\alpha}^{-1 / 4}
$$

where the Rayleight number is defined as

$$
K_{\alpha}^{\prime}=\frac{g|\beta|}{\alpha v} D^{3} \Delta T^{*} .
$$

The dimensions are normalized by using

$$
\xi=x / D, \quad \eta=q / \delta
$$

and

$$
\delta=\delta^{*} / G(\xi)
$$

where $G(\xi)$ is non-dimensional boundary-layer thickness.

The velocity and temperature profiles of boundary layer region are ass umed to match the required boundary conditions at $\eta=0$ and 1 . These are

$$
\begin{gathered}
u=U^{*} F(\xi) \eta(1-\eta)^{2}+V_{\mathrm{c}} \sin \theta \eta\left(1+\eta-\eta^{2}\right) \\
\psi:=\Delta T^{*} J(\xi) \eta(2-\eta)
\end{gathered}
$$

where $F(\xi)$ and $J(\xi)$ are non-dimensional similarity parameter to be determined. The value of $\beta$ can be obtained by assuming the density be a linear function of temperature, so that

$$
\begin{aligned}
\int_{0}^{1} \frac{\rho_{\mathrm{c}}-\rho}{\rho} \mathrm{d} \eta & =\int_{0}^{1} \beta \psi \mathrm{d} \eta \\
& =\frac{2}{3} \beta \Delta T^{*} J
\end{aligned}
$$

From equations (3) and (5), the core velocity, $V_{c}$, can be eliminated and the resulting set of equations are

$$
\frac{F}{G} \frac{\mathrm{d} J}{\mathrm{~d} \xi}=-6 \sin \theta\left(1-\frac{5 \varepsilon}{6}\right)
$$

$\frac{G}{P_{\mathrm{r}}} \frac{\sin \theta}{105} \frac{\mathrm{d}}{\mathrm{d} \xi}\left(\frac{F^{2}}{G}\right)=\frac{\sin \theta}{|\beta| \Delta T^{*}} \int_{0}^{1} \frac{\rho_{\mathrm{c}}-\rho}{\rho} \mathrm{d} \eta-G^{2} F\left(1-\frac{\varepsilon}{6}\right)$

$\sin \theta \frac{\mathrm{d}}{\mathrm{d} \xi}\left[\frac{J F}{G}\left(1-\frac{29 \varepsilon}{13}\right)\right]-\sin \theta J \frac{\mathrm{d}}{\mathrm{d} \xi}\left[\frac{20}{12} \frac{F}{G}\left(1-\frac{7 \varepsilon}{6}\right)\right]$

$+\varepsilon=-40 G J$

where

$$
\varepsilon=\frac{1}{\left(G R_{\alpha}^{1 / 4}\right)}
$$

Then using the assumption of large Prandtl number, $P r \cong 11.35$ at $-4^{\circ} \mathrm{C}$, the L.H.S. term in equation (11) may be neglected. Also neglecting terms of order $\varepsilon$, equations (10) and (11) can be substituted into equation (12) to give a single equation for the variation of the temperature, $J$, along the vertical axis of the cylinder as

$$
\begin{aligned}
-\frac{4}{3} \cos \theta J^{\prime} J+\sin ^{2} \theta\left(J^{\prime 2}\right. & \left.+\frac{2}{3} J J^{\prime \prime}\right) \\
& =\frac{20}{3}\left(\frac{1}{18}\right)^{1 / 3} J^{4 / 3}\left( \pm J^{\prime}\right)^{1 / 3}
\end{aligned}
$$

where the primes indicate differentiation with respect of $\xi$. In the term on the R.H.S. of equation (13) the positive sign applies for $\beta$ positive and the negative sign for $\beta$ negative. The conditions necessary for the existence of a real solution to equation (13), when $\beta$ is positive, are

$$
\begin{gathered}
J=0, \quad \xi=0, \\
J J^{\prime 4}= \pm \frac{18}{125}, \quad \xi=1 .
\end{gathered}
$$

For $\beta$ negative these conditions are interchanged. With these conditions no additional boundary conditions are required. The resulting equations were solved by using nonlinear finite difference method and numerical iteration to calculate values of $J$ at 20 points between $0<\xi<1$. The value of $J$ on the center line of the cylinder, $J_{\mathrm{CL}}(1 / 2)$, which will be required in $s u b$ sequent calculations, is 0.464 . Substituting the $J_{\mathrm{CL}}$ into equation (8), we could calculate the value of the tempcraturc difference

$\psi_{\mathrm{CL}}$ as

$$
\psi_{\mathrm{CL}}=T_{\mathrm{CL}}-T_{\mathrm{wall}}=0.464 \Delta T^{*}
$$

Since

$$
\Delta T^{*}=\frac{D^{2} H}{\alpha} R_{\alpha}^{-1 / 4}
$$

and

$$
R_{\alpha}={ }_{\alpha v}^{g|\beta|} D^{3} \Delta T^{*}=\left(\begin{array}{c}
g|\beta| H \\
\alpha^{2} v
\end{array}\right)^{4 / 5} D^{4}
$$

Equation (15) becomes the following form 


$$
H=C_{\mathrm{T}}\left(\frac{T_{\mathrm{CL}}-T_{\text {wall }}}{D}\right)^{5 / 4}
$$

where

$$
C_{\mathrm{T}}=2.62\left(\frac{\alpha^{3} g|\beta|}{v}\right)^{1 / 4} .
$$

Equation (16) presents the relationship between cooling rate of water, temperature difference between the locations of cylinder center line and inner wall, and inside diameter of cylinder.

\section{RESULTS AND DISCUSSION}

In this study, a series of experimental observation and measurement are performed to investigate the effect of water under various factors on the supercooling phenomenon and the freezing probability. These factors are the cooling rate at which the test cylinder is exposed to, the inside diameter of the test cylinder, and the addition of different nucleation agents.

\section{Effect of cooling rate on supercooling phenomenon and freezing probability}

The complete cooling process associated with natural convective motion, dendritic ice formation, and solidification was first illustrated by using an $82.8 \mathrm{~mm}$ cooper cylinder as the test cell. The water in the test cell was initially at a thermal equilibrium temperature of $21^{\circ} \mathrm{C}$ and the inlet coolant temperatures were adjusted at various temperatures to control the cooling rate of water. The experiment was started by suddenly circulating the coolant through the cooling chamber and the time variations of the temperature at various locations were recorded.

Figure 4 shows the time histories of the water temperature at different locations inside the horizontal cylinder under the condition of moderate cooling rate $\left(T_{\text {f, in }}=-10.5^{\circ} \mathrm{C}, H=1.5^{\circ} \mathrm{C} \mathrm{min}^{-1}\right)$. The cooling process can be divided into three regions: the region of water sensible cooling, the region of dendritic ice formation, and the solidification region. During the region of water sensible cooling, natural convection is the dominated heat transfer mechanism. This figure shows clearly the inversion process occurring near $4^{\circ} \mathrm{C}$ in the sensible cooling region. Due to the density inversion effect of water, the temperature at the top of the cylinder becomes the cold spot in the cylinder. As further cooling occurs, some extent of water at the top of the cylinder was supercooled. When the cold spot reaches the nucleation temperature of water (in the case of about $-6^{\circ} \mathrm{C}$ ), ice nucleation occurs at the upper part of the cylinder. The dendritic ice spreads rapidly from the nucleation site down toward the center region of the cylinder and, meanwhile, it also grows down along the cold boundary layer region adjacent to the inner cylinder surface. Since the water inside the cylinder comes into contact with the inner cylinder surface, its nucleation phenomenon is regarded as a heterogeneous nucleation. The total time required for the whole dendritic ice growth to be completed is less than $1 \mathrm{~s}$. In this case, the dendritic ice is formed only in the supercooled region and does not result in a cylinder blockage. During the region of dendritic ice growth, a large amount of latent heat is released into the supercooled water. This energy causes the temperature of supercooled water to rise suddenly from $-6^{\circ} \mathrm{C}$ to its freezing point, $0^{\circ} \mathrm{C}$. After the water temperature returns to $0^{\circ} \mathrm{C}$, no more dendritic ice growth occurs. Then the third region of an annulus solid ice begins to grow slowly from the inside wall of the cylinder to the center region. In the solidification region, conduction is the dominated heat transfer mechanism and cool thermal energy is stored in the form of latent energy. The time required for complete solid ice growth is about $117 \mathrm{~min}$ in this case.

Figure 5 shows the case of higher cooling rate $\left(T_{\mathrm{f}, \text { in }}=-18^{\circ} \mathrm{C}, H=3.2^{\circ} \mathrm{C} \mathrm{min}^{-1}\right)$. Since the cooling rate is higher than that of $T_{\mathrm{f}, \text { in }}=-10.5^{\circ} \mathrm{C}$, only a very small amount of dendritic ice appears at the top site adjacent to the inner wall of the cylinder. The region of dendritic ice formation cannot be easily observed, and the cooling process changes directly from the sensible cooling region to the solidification region. Because the temperature difference between the water and outer coolant is larger than that of $T_{f, \text { in }}=-10.5^{\circ} \mathrm{C}$, the total time required for complete solidification (about $66 \mathrm{~min}$ ) is less than the first case.

Figure 6 illustrates the case of lower cooling rate ( $T_{\text {f.in }}=-6^{\circ} \mathrm{C}, H=0.5^{\circ} \mathrm{C} \mathrm{min}^{-1}$ ). Due to low cooling rate, the temperature of water at the top region needs more time $(46.7 \mathrm{~min})$ to reach the nucleation temperature as compared with the case of $T_{\mathrm{f}, \text { in }}=-10.5^{\circ} \mathrm{C}$ $(16.7 \mathrm{~min})$. Therefore, the extent of supercooled water under this case is larger than that of $T_{\mathrm{f} \text {, in }}=-10.5^{\circ} \mathrm{C}$. As the ice nucleation occurs (in this case about $-5.7^{\circ} \mathrm{C}$ ), the dendritic ice grows quickly and fills the entire cylinder. The total time required in the solidification region is about $173 \mathrm{~min}$ and is expected to be longer than the above two cases.

As the inlet coolant temperature is adjusted at $-5^{\circ} \mathrm{C}$, which is higher than the nucleation tempcrature of water $\left(-5.2--9^{\circ} \mathrm{C}\right)$, the cooling process is shown in Fig. 7. In this case, it will be difficult for ice nucleation to take place and all the water is under the supercooled state. Hence the entire water in the cylinder will be maintained at a metastable state and the energy is stored only by sensible heat. Therefore, only a water sensible cooling region can be observed in this case. This implies that it is necessary to let the inlet coolant temperature be lower than $-5.2^{\circ} \mathrm{C}$ for the latent heat storage.

The photographs of the final extent of dendritic ice growth in the test cylinder corresponding to the cooling rates of $1.7,1.5$ and $0.5^{\circ} \mathrm{C} \mathrm{min}{ }^{-1}$ are shown in Fig. 8. As can be seen in the figure, the extent of dendritic ice formation for the cooling rate of $0.5^{\circ} \mathrm{C}$ $\mathrm{min}^{-1}$ is more than that of $1.7^{\circ} \mathrm{C} \mathrm{min}^{-1}$. Since the 


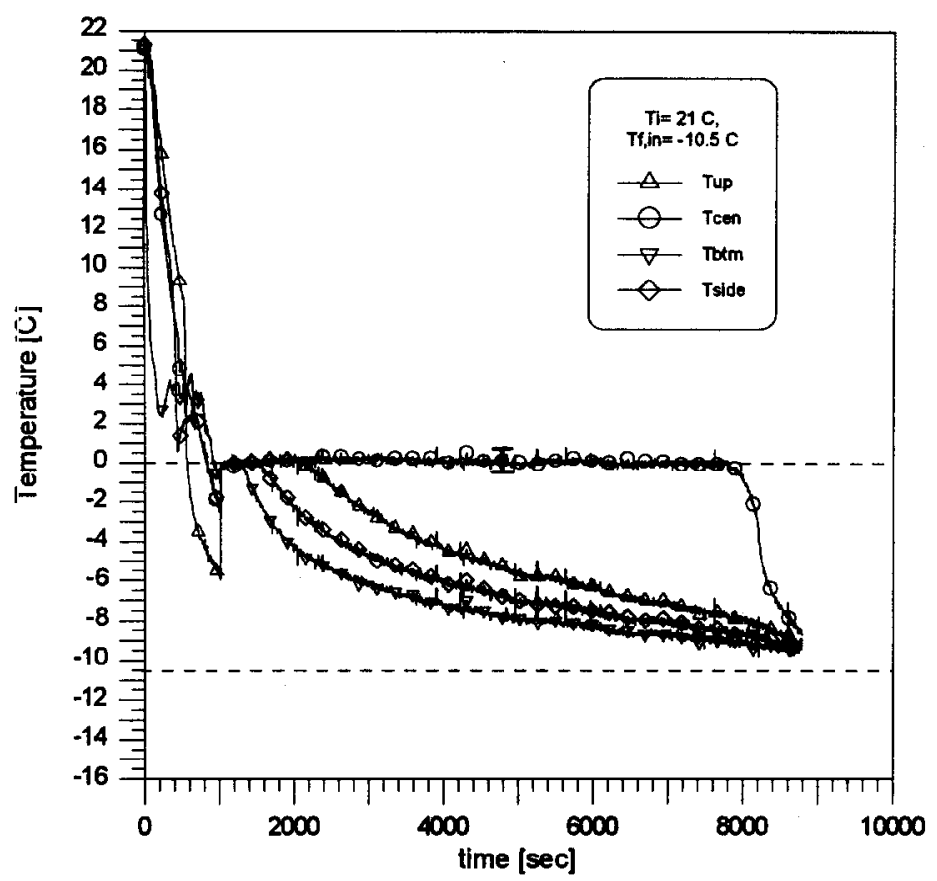

Fig. 4. Time variation of temperature profiles for $T_{\mathrm{f}, \mathrm{in}}=-10.5^{\circ} \mathrm{C}$ at different locations $\left(H=1.5^{\circ} \mathrm{C} \min ^{-1}\right)$.

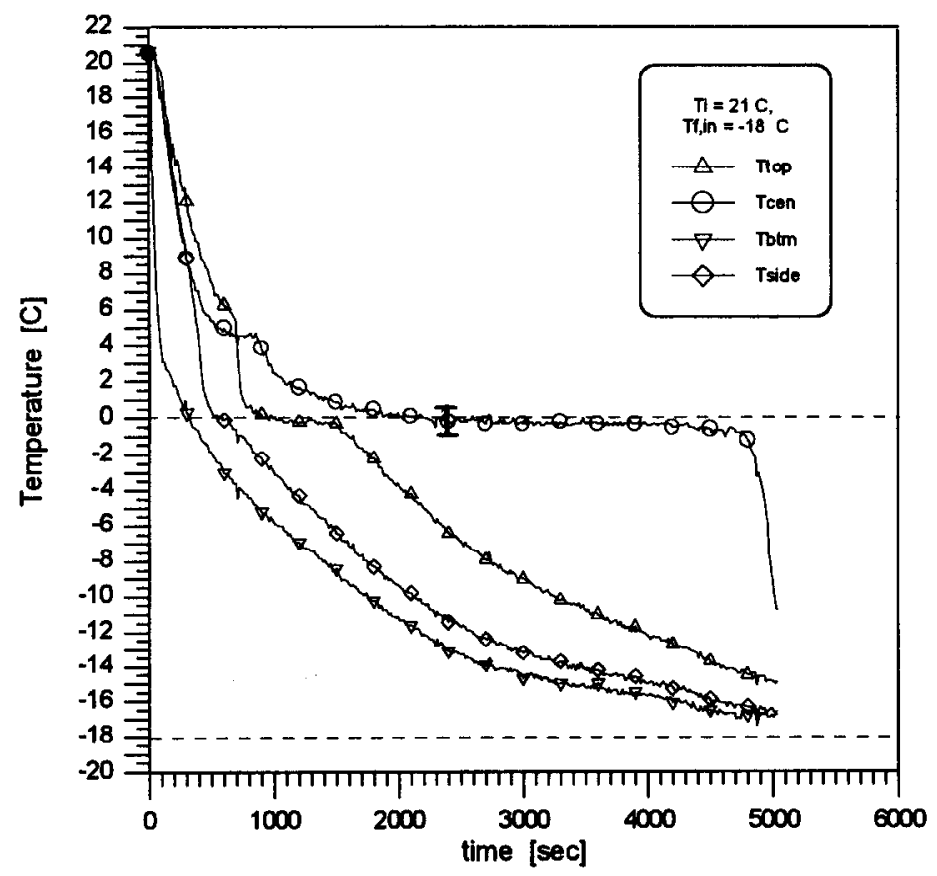

Fig. 5. Time variation of temperature profiles for $T_{\mathrm{f}, \mathrm{in}}=-18^{\circ} \mathrm{C}$ at different locations $\left(H=3.2^{\circ} \mathrm{C} \mathrm{min}^{-1}\right)$.

dendritic ice grows only in the supercooled region of water, a greater extent of supercooled water will result in more dendritic ice. Therefore, the low cooling rate is much more likcly to be blocked by dendritic ice than the case of the high cooling rate under the same inside diameter.

It is obvious that the inlet coolant temperature and the cooling rate have a great influence on water nucleation inside the horizontal container. The prob- ability distribution curves under the conditions of different inlet coolant temperature (from -3 to $-10^{\circ} \mathrm{C}$ ) are shown in Fig. 9. Every dot marked in the figure represents the results of 24 times of experiments, each of which lasted $5 \mathrm{~h}$ at most. The definition of freezing probability is $P=[($ the number of freezings)/(the number of total tests)]. The results indicate that the lower the coolant temperature, the greater the probability of nucleation. The coolant temperature 


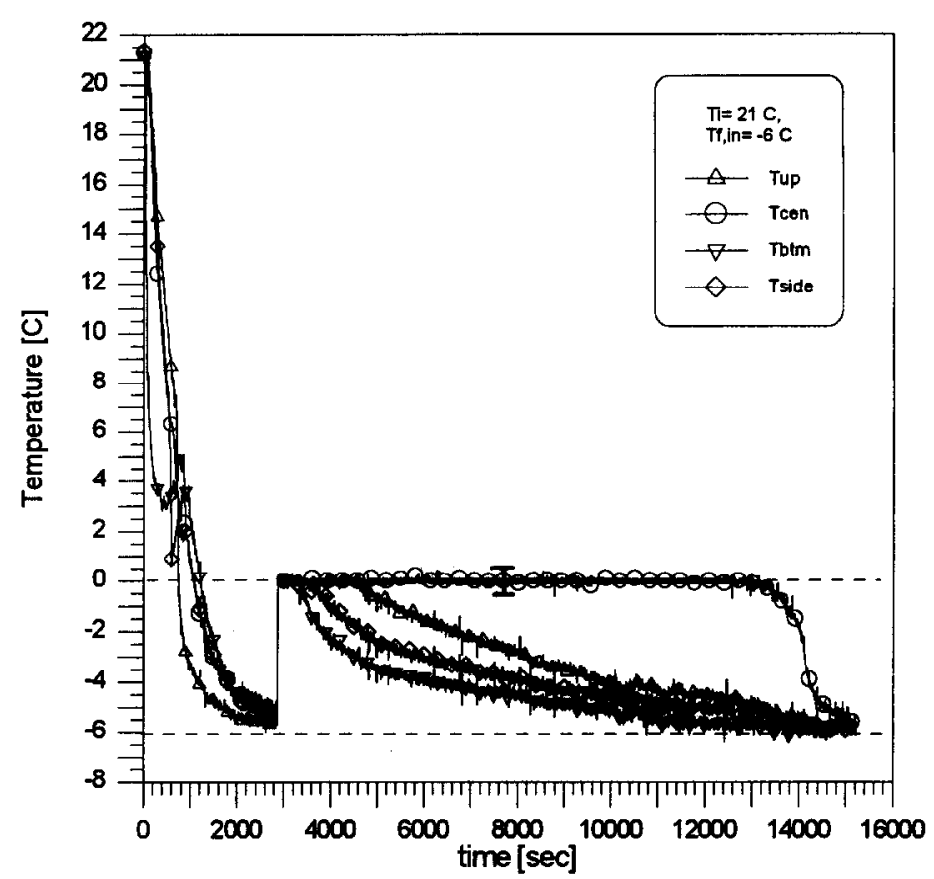

Fig. 6. Time variation of temperature profiles for $T_{\mathrm{f}, \mathrm{in}}=-6^{\circ} \mathrm{C}$ at different locations $\left(H=0.5^{\circ} \mathrm{C} \mathrm{min}^{-1}\right)$.

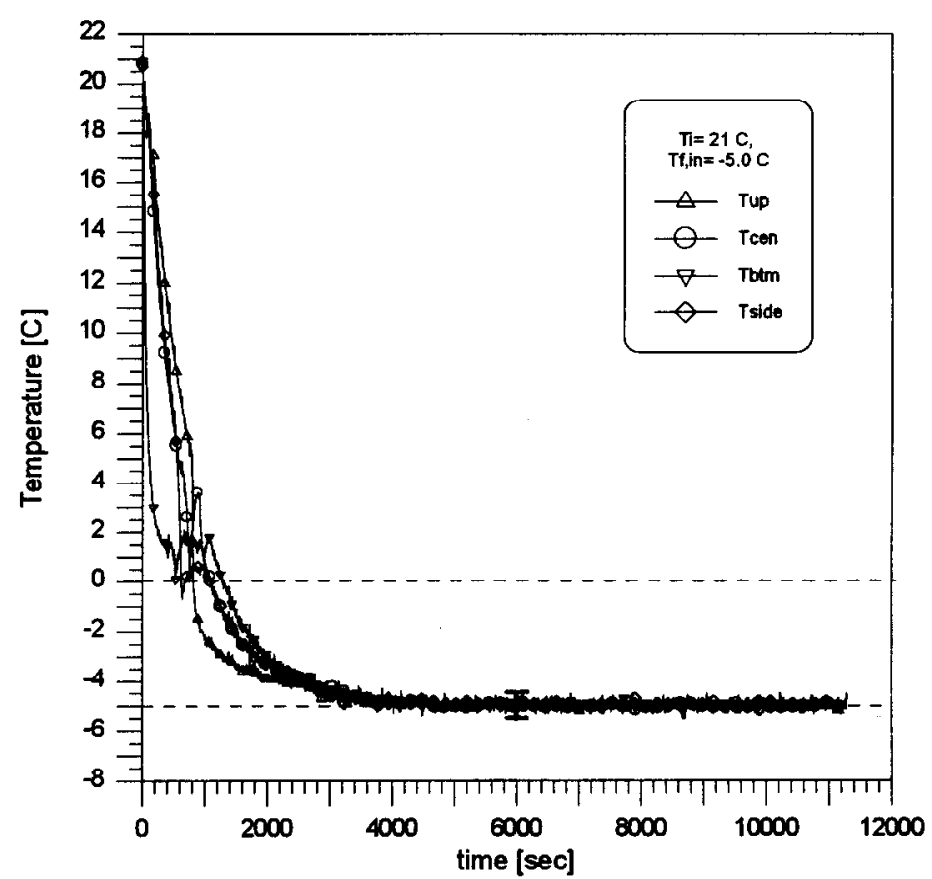

Fig. 7. Time variation of temperature profiles for $T_{\mathrm{f}, \mathrm{in}}=-5^{\circ} \mathrm{C}$ at different locations $\left(H=0.38^{\circ} \mathrm{C} \mathrm{min}{ }^{-1}\right)$.

ranges from $-4^{\circ} \mathrm{C}$ with the probability of zero, to $-9^{\circ} \mathrm{C}$ with the probability of one, showing a temperature range of about $5^{\circ} \mathrm{C}$. In view of cool storage air-conditioning system utilizing pure water as PCM, if the inlet coolant temperature is higher than $-4^{\circ} \mathrm{C}$ then the cool energy will be stored in the form of sensible heat. If the entrance temperature falls within the range of nucleation probability, then some of the containers will continue to exist in the metastable state without freezing. Therefore, if one wants to store the thermal energy in the form of latent heat, the inlet coolant temperature must be lower than $-9^{\circ} \mathrm{C}$. However, this process will compromise the efficiency of the chiller unit, and increase the system operation cost.

Effect of inside diameter on supercooling phenomenon and freezing probability

In addition to the effect of cooling rate, the cylinder diameter is also an important factor on the supercooling phenomenon of dendritic ice growth inside 

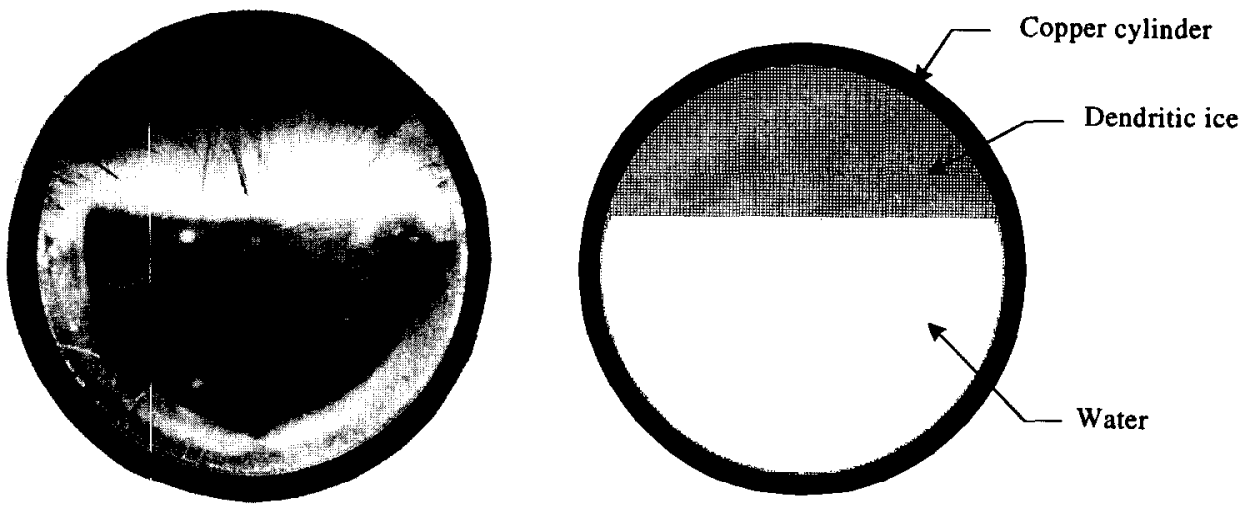

(a)
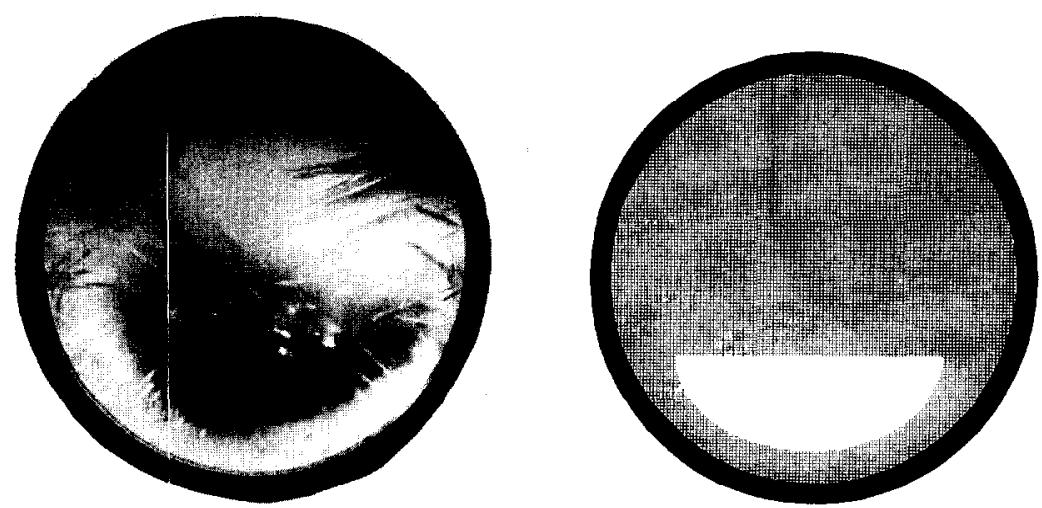

(b)
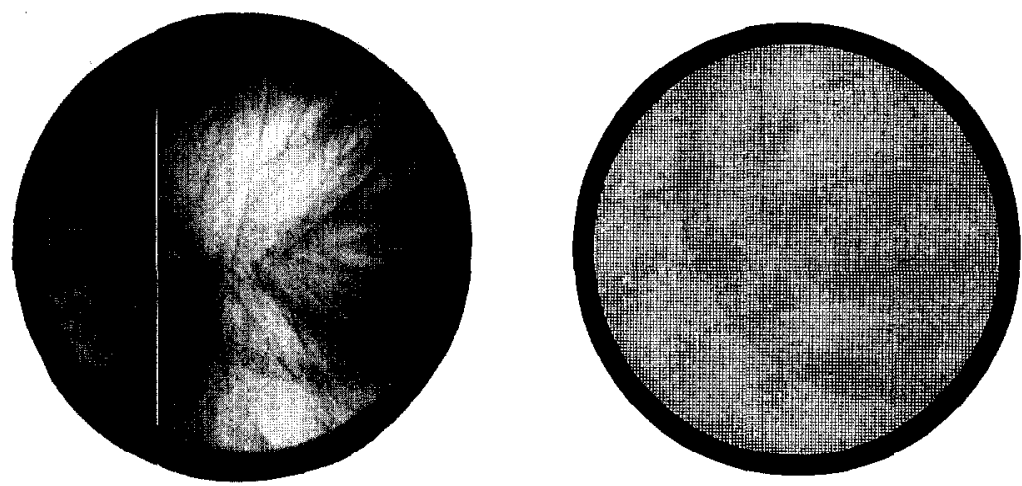

(c)

Fig. 8. Effects of cooling rate on the extent of dendritic ice growth in the horizontal cylinder with the same inside diameter $(D=82.8 \mathrm{~mm})$ : (a) $H=1.7^{\circ} \mathrm{C} \mathrm{min}-1$, (b) $H=1.5^{\circ} \mathrm{Cmin}^{-1}$, (c) $H=0.5^{\circ} \mathrm{C} \mathrm{min}^{-1}$. 

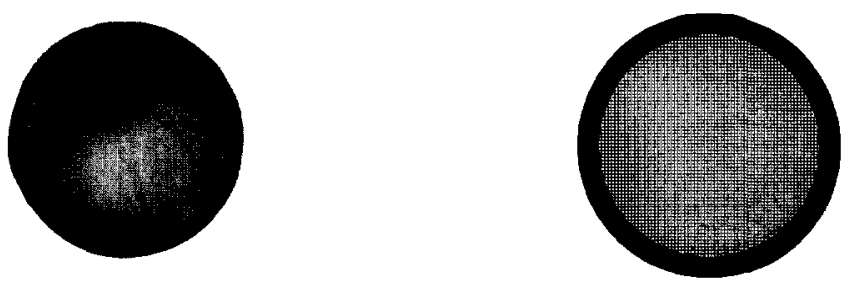

(a)
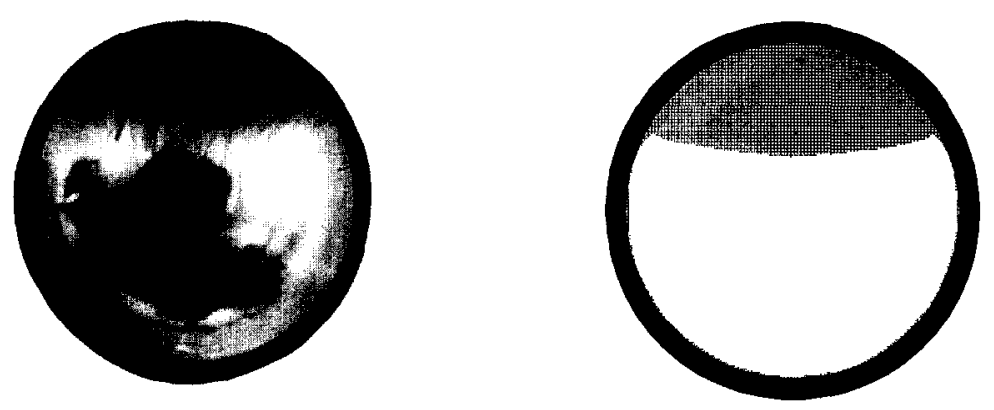

(b)
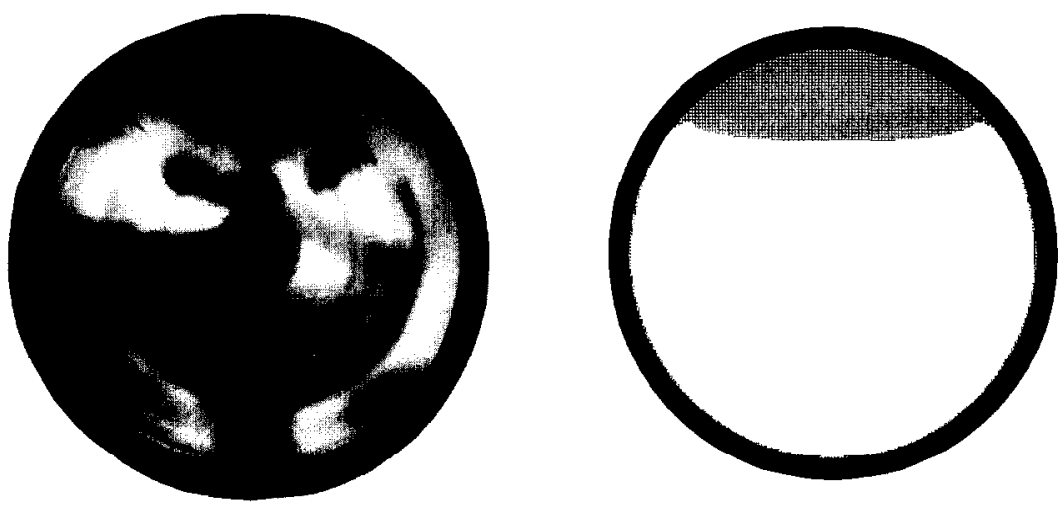

(c)

Fig. 10. Effect of inside diameter of cylinder on the extent of dendritic ice growth under the same cooling rate $\left(H=2.0^{\circ} \mathrm{C} \mathrm{min}^{-1}\right):$ (a) $D=38.0 \mathrm{~mm}$, (b) $D=62.4 \mathrm{~mm}$, (c) $D=82.8 \mathrm{~mm}$. 


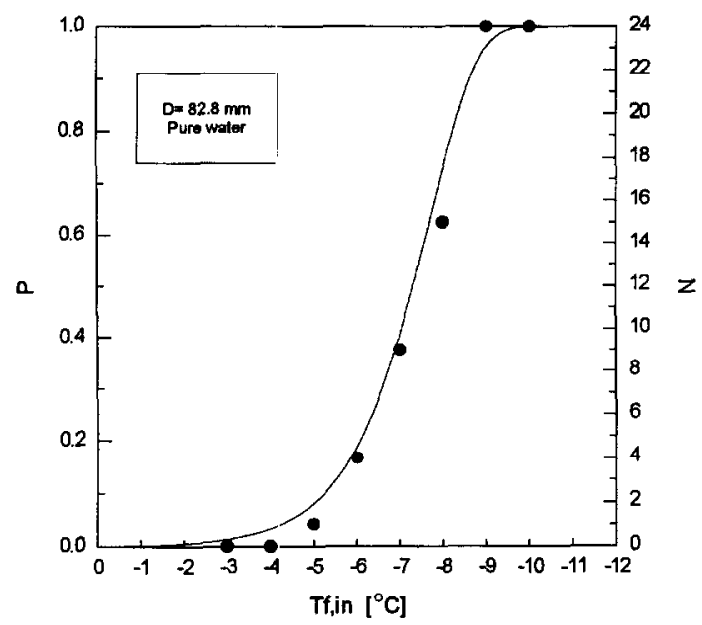

Fig. 9. Distribution curve of freezing probability of water inside a cylinder with diameter of $82.8 \mathrm{~mm}$ under different inlet coolant temperatures.

the container. To investigate the influence of the inside diameter of the cylinder, a series of experiments were conducted by using three different inside diameters $(82.8,62.4$ and $38.0 \mathrm{~mm})$. The same procedure presented above was used. Figure 10 shows three photographs of the final extent of dendritic ice growth of different cylinder diameters under the same cooling rate $\left(2.0^{\circ} \mathrm{C} \mathrm{min}^{-1}\right)$. As shown in the figure, the smaller cylinder is much more likely to be blocked by dendritic ice than the larger one under the same cooling rate. This is due to the fact that the smaller cylinder has more water to be supercooled than the larger one under the same cooling rate.

It is obvious that from the above discussion of the effect of cooling rate and inside diameter on supercooling phenomenon, there exists a critical cooling rate for dendritic ice blockage. From the results of our experimental measurements and photographic observations, the water temperature at the center of the cylinder will determine whether the cylinder will be blocked by dendritic ice or not. It was found that if the center temperature approaches $-3^{\circ} \mathrm{C}$ or lower, even for different cylinder diameters, the cylinder will be completely blocked by dendritic ice. That is, the critical condition for a cylinder blocked by dendritic ice is that the center of the cylinder must be cooled to $-3^{\circ} \mathrm{C}$. Alternatively, if the water temperature at the center site is higher than $-3^{\circ} \mathrm{C}$, a complete blockage will not occur.

According to our experimental measurements, ice nucleation occurs in the range of $-5.2--8.8^{\circ} \mathrm{C}$. As the nucleation occurs, the wall temperature on the top of the horizontal cylinder is the lowest in the entire container water. In this moment the top wall temperature is equal to the nucleation temperature of water. Taking $-7^{\circ} \mathrm{C}$ as the nucleation temperature $T_{\mathrm{n}},-3^{\circ} \mathrm{C}$ as the center temperature $T_{\mathrm{CL}}$, the combining with equation (16), the critical condition for dendritic ice blockage can be specified. The expression for the critical cooling rate is of the form

$$
H_{\mathrm{cri}}=C_{\mathrm{T}}\left(\frac{T_{\mathrm{CL}}-T_{\mathrm{n}}}{D}\right)^{5 / 4}=C_{\mathrm{T}}\left(\frac{4}{D}\right)^{5 / 4}
$$

where constant $C_{\mathrm{T}}$ is defined in equation (17) and is approximately in the range of $1.53-1.8 \mathrm{~cm}^{5 / 4} \mathrm{~min}^{-1}$ $\mathrm{K}^{-1 / 4}$. Substituting the maximum and minimum values of $C_{1}$ into equation (18), we obtain two curves as given in Fig. 11. The left regime of the lower curve represents the condition of complete blockage under the corresponding cylinder diameters and cooling rates, and the right regime of the upper curve represents the incomplete blockage condition. Also shown in the figure are symbols indicating the extent of dendritic ice growth for various cylinder diameters and cooling rates from our experimental observation. For the case of the same cylinder diameter, increasing in cooling rate decreases the extent of dendritic ice in the cylinder. At the same cooling rate, the increase in cylinder diameter will decrease the extent of dendritic ice. The critical cooling rate for the larger cylinder is less than that of the smaller one. The results of Gilpin [2] are also shown in this figure to be compared. The values of constant $C_{T}$ obtained by Gilpin are in the range of $1.18-1.63 \mathrm{~cm}^{5 / 4} \mathrm{~min}^{-1} \mathrm{~K}^{-1 / 4}$.

Supercooling period of water in the cylinder can be defined as

$$
(\Delta t)_{\mathrm{s}}=t_{2}-t_{1}
$$

where $t_{1}$ is the time when the water temperature at the top location reaches $0^{\circ} \mathrm{C}$, and $t_{2}$ is the time when the ice nucleation occurs at that site. From equation (2), we have

$$
0=T_{\mathrm{wi}}-H t_{1}
$$

and

$$
T_{\mathrm{n}}=T_{\mathrm{w} i}-H t_{2} .
$$

After solving the upper two equations, we obtained

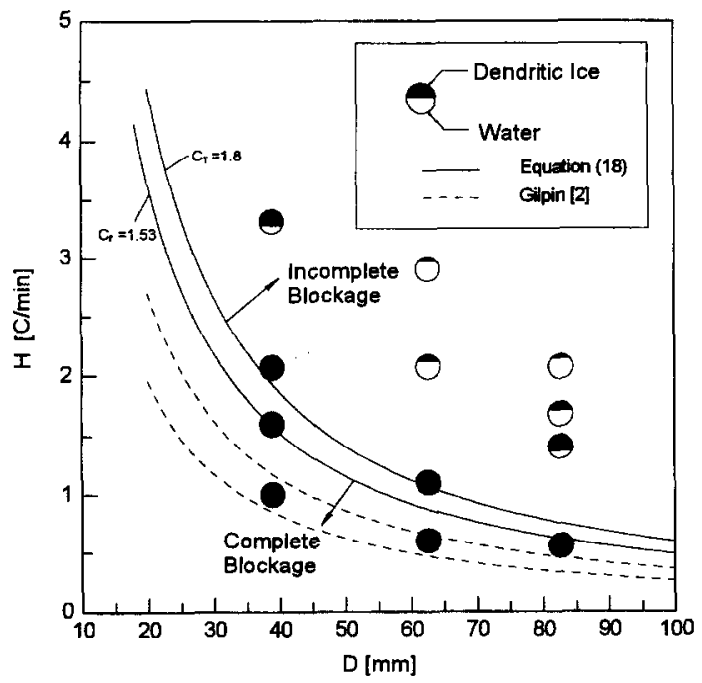

Fig. 11. Critical condition of dendritic blockage map in horizontal cylinders. 


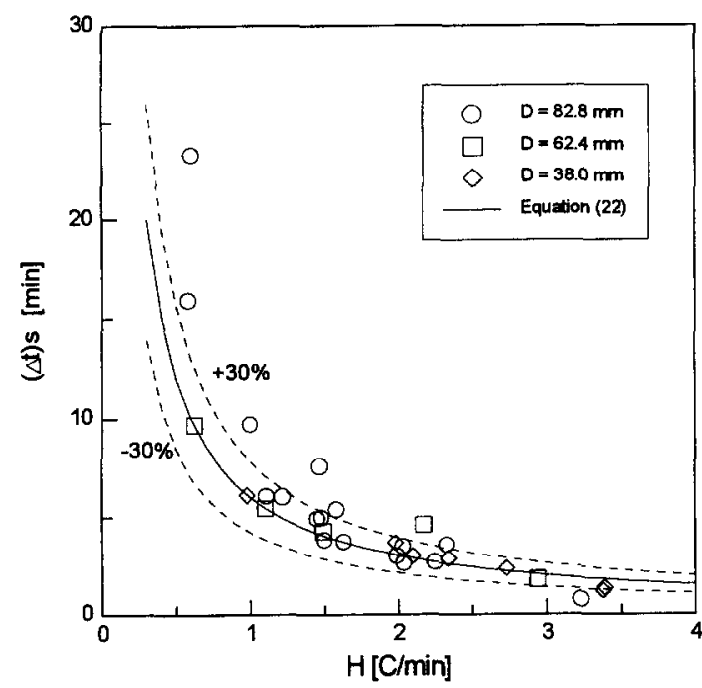

Fig. 12. Comparison of the theoretical supercooling period as a function of conling rate with experiment results.

the relationship between the supercooling period, the nucleation temperature, and the cooling rate as

$$
(\Delta t)_{\mathrm{s}}=\frac{-T_{\mathrm{n}}}{H} .
$$

From experimental measurements, the average nucleation temperature of pure water is about $-7^{\circ} \mathrm{C}$. Using this value as nucleation temperature, equation (22) can be plotted as the solid line, as shown in Fig. 12. The experimental results are also shown on the figure and are compared with the prediction of equation (22). As shown in Fig. 12, equation (22) can predict well the experimental results within $\pm 30 \%$ except the case of $82.8 \mathrm{~mm}$ with a cooling rate of less than $1.5^{\circ} \mathrm{C} \mathrm{min}^{-1}$.

A series of probability experiments involving five sizes of cylindrical containers with inside diameter 124 , $82.8,55,47$ and $32 \mathrm{~mm}$ were also conducted to explore the effect of water volume contained on the nucleation probability. The experimental results are shown in Fig. 13, which indicate that the larger the volume of water contained, the greater the probability of nucleation. Under the metastable state, the cmbryos congregated by water molecules inside the container are in the unstable state with dendritic formation or disintegration. Nucleation is the initial appearance of the formation of stable crystal nucleus due to the fluctuation of free energy. Embryos with a larger size have a greater chance to become stable nucleus. The testing cylinder with a larger volume of water contains a great number of water molecules. The number of large size embryos is thus relatively increased. As a result, the probability of forming a stable nucleus is greater, and the nucleation temperature also rises. It can also be observed from Fig. 13 that the volume of water contained increases, the nucleation probability also rises correspondingly till a certain ultimate value (about ID $=82.8 \mathrm{~mm}$ ). At this time, even additional increase

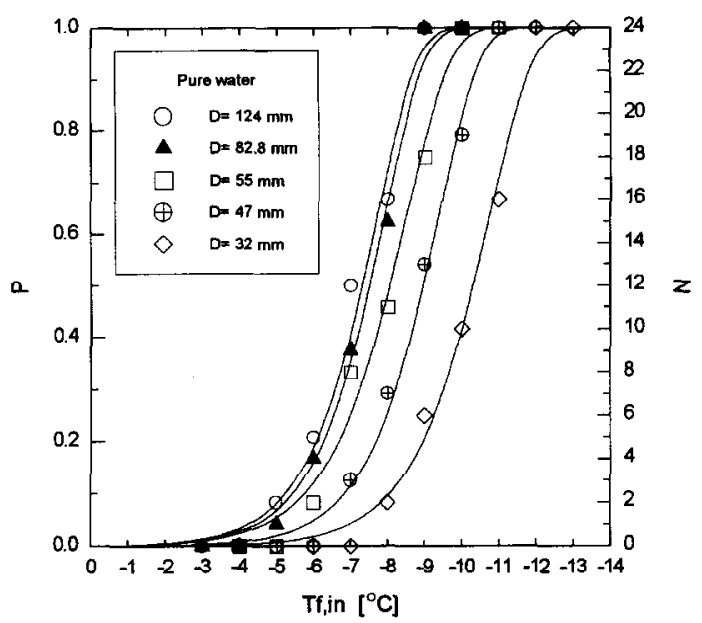

Fig. 13. Distribution curves of freezing probability with different water volume contained.

of the water volume $(82.8-124 \mathrm{~mm})$ cannot raise the nucleation temperature of water anymore.

\section{Effect of different nucleation agents on nucleation and freezing probability}

As far as a cool storage air-conditioning system using latent heat is concerned, it is necessary to lower the entrance coolant temperature below the nucleation temperature. If the water nucleation temperature can be raised, the release of supercooling can be accelerated to enter the latent heat thermal storage process earlier. Among the many improvement methods, the addition of a nucleation agent is one of the approaches to effectively improve the supercooling phenomenon. Figure 14 shows the probability curves of the addition of different percentages of nucleation agents, which are iron ore (nucleation agent $A$ ), river sand (nucleation agent B), iron chip (nucleation agent $C$ ), and silver iodide (AgI). Regardless of the type of nucleation agent, the probability curve shifts to the left with an increase of the mass ratio of nucleation agent. As shown in Fig. 14(a), the mass ratio of nucleation agent $\mathrm{A}$ is $0.05,0.1,1,5$ and $10 \%$. The comparison among the nucleation probability of various mass ratios suggest that after the addition of the nucleation agent, the mean nucleation temperature of the container is higher than the nucleation temperature of pure water. In addition, as the quantity of nucleation agent increases, the mean nucleation temperature also rises as a result till a certain ultimate value (about 1\%). At this time, even the additional increase of the nucleation agent (1-10\%) cannot raise the nucleation temperature of water anymore. Though the addition of nucleation agents in the container water do facilitate nucleation, not all added agents have the same effect. In terms of the overall effect of nucleation facilitation, the comparison among four types of agent indicates that AgI was the best effect, followed by agent $A$, agent $B$, and agent $C$, which shows the poorest effect. The reason for the above 


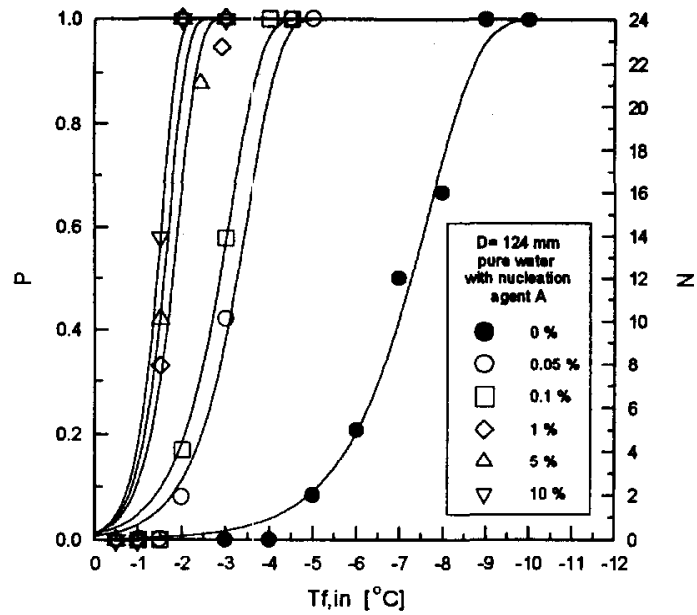

(a)

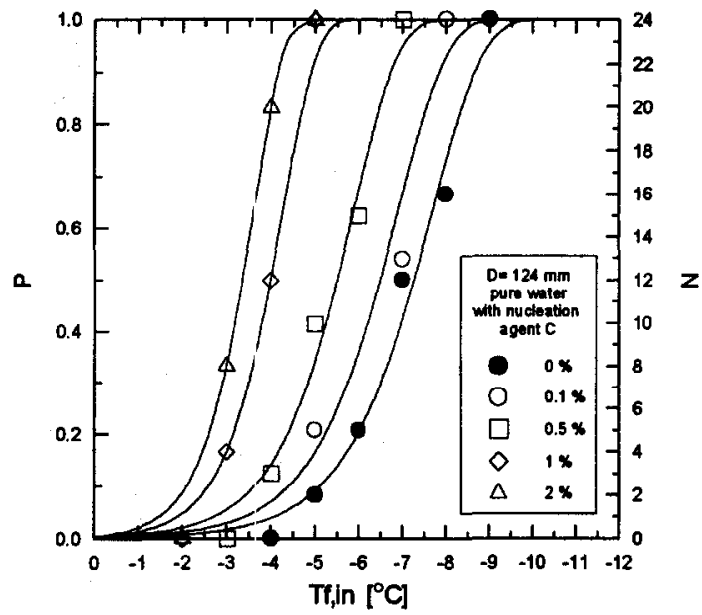

(c)

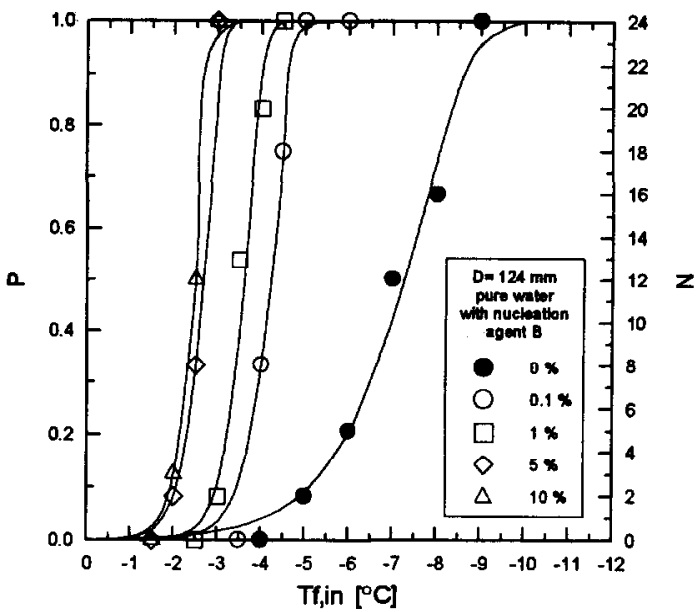

(b)

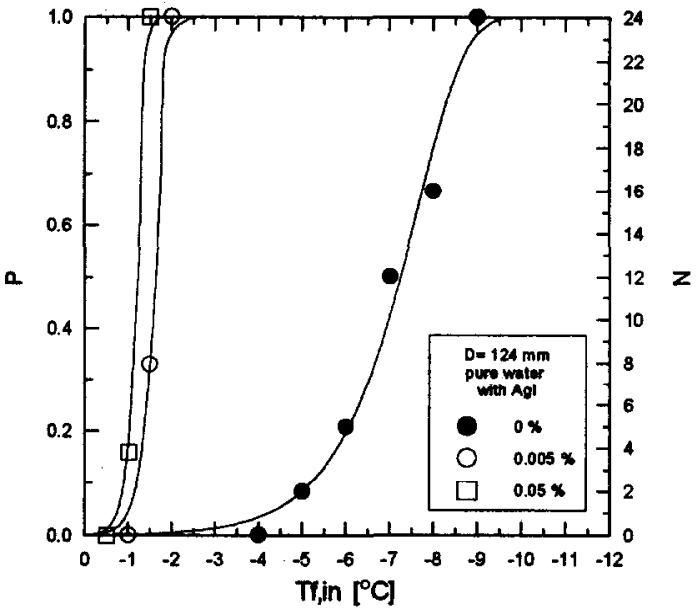

(d)

Fig. 14. Distribution curves of freezing probability of water added with different percentages of (a) nucleation agent $\mathrm{A}$, (b) nucleation agent $\mathrm{B}$, (c) nucleation agent $\mathrm{C}$, (d) nucleation agent AgI.

phenomena may be related to the micro surface conditions, chemical characteristics and molecular crystal structure of the nucleation agents. As far as water added with nucleation agent is concerned, the water contained not only comes in contact with the inner surface of cylinder, but also the surface of nucleation agent in the bottom, which forms a new interface. Before any nucleation agent is added, water nucleation is affected by the inner surface properties of cylinder. After an agent is added, water nucleation is affected by both the inner surface properties of cylinder and the properties of the contact interface with the nucleation agent. The properties with the nucleation agent have a greater impact on facilitating water nucleation than the inner surface of cylinder.

To further investigate the reason, a small amount of nucleation agents $\mathrm{A}, \mathrm{B}$ and $\mathrm{C}$ was taken for photography after magnification by scanning electron microscope (SEM) to observe their surface characteristics. Figure 15 shows the photographs of these three nucleation agents after the magnification of 11,88 and 700 times. The picture is divided into two sections: the left section denotes 11 times of magnification; while the right section denotes 88 times of magnification of the small square portion in the left section. The picture on the right shows a magnification of 700 times. Care comparison among the surface structures of the three nucleation agents shows that agent $A$ has the most coarse surface, followed by agent $B$, and agent $C$ which has the smoothest surface. These findings suggest that the coarser the surface structure, the easier it is to achieve nucleation. 


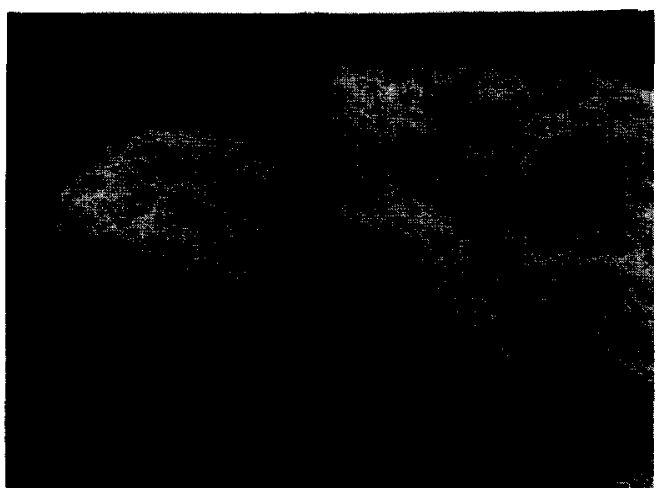

(a)

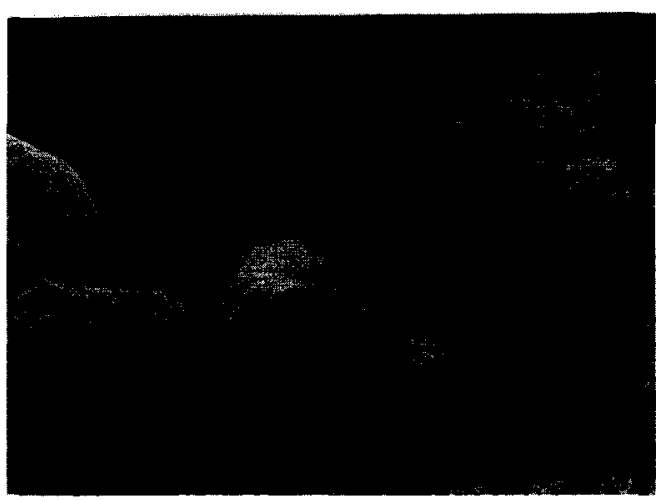

(c)

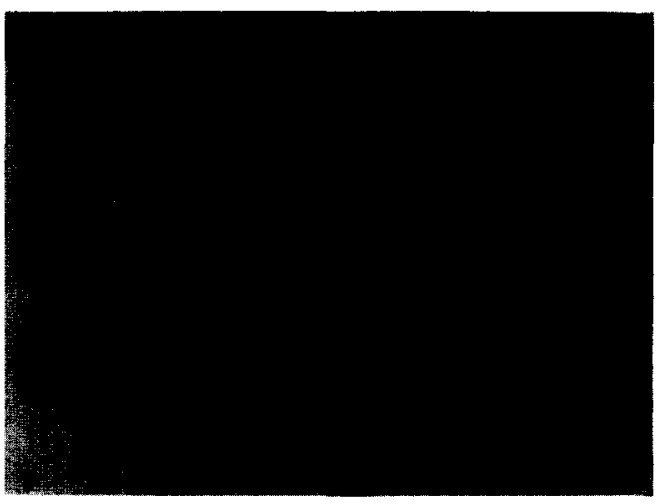

(e)

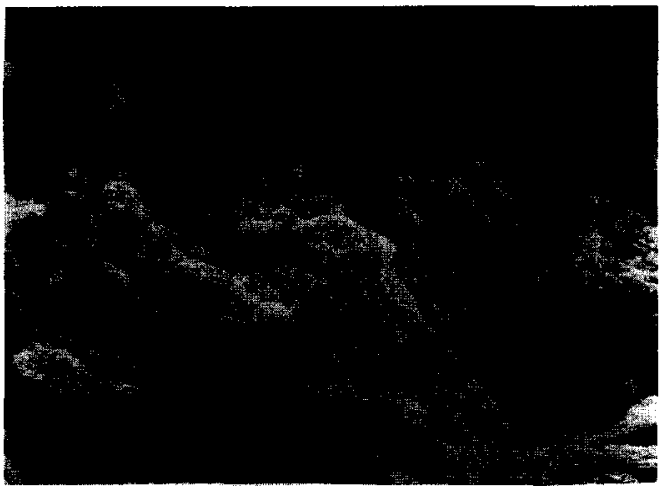

(b)

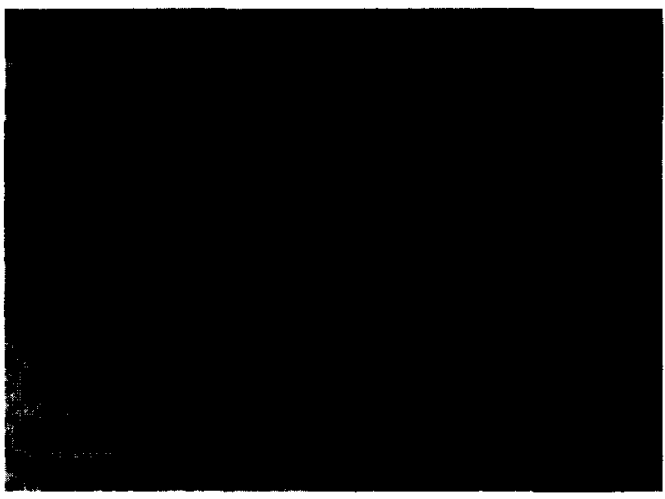

(d)

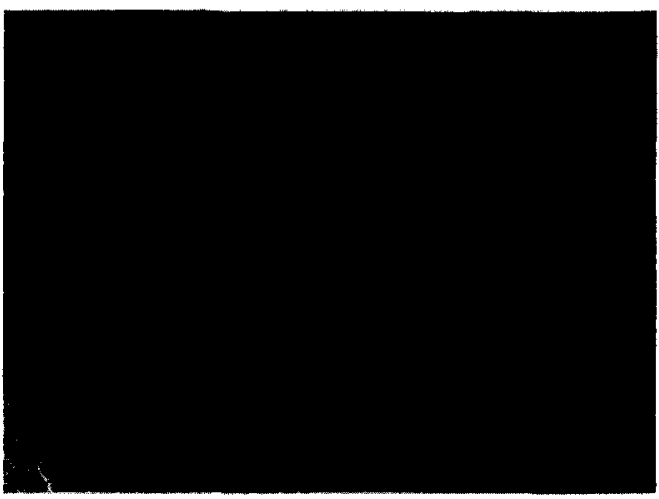

(f)

Fig. 15. Surface characteristics of (a) (b) nucleation agent A, (c)(d) nucleation agent $B$, and (e)(f) nucleation agent $\mathrm{C}$.

Due to the chemical properties of AgI, evaporation occurs when it receives an electric beam from SEM. It is thus very difficult to observe AgI through SEM, or compare it with other nucleation agents. However, in the field of atmospheric science, AgI has long been proved effective in facilitating the nucleation of droplets in atmospheric mist, and thus become a major nucleation agent in realizing manmade rainfall. Related literature [9] also reports that the structure of $\mathrm{AgI}$ is very similar to that of ice and both are hexagonal crystal structures. Therefore, it is extremely casy for ice embryos to attached onto AgI and bccomc stable nucleus.

\section{CONCLUSION}

A series of experiments related to the supercooling phenomenon and the freezing probability of water inside horizontal cylinders is conducted in this study. Some macro perspective parameters as cooling rate, diameter of test cylinders, and addition of different nucleation agents are manipulated to investigate the 
effect of above factors on the nucleation behavior of water inside enclosed containers. The results show that the lower the coolant temperature, the greater the probability of nucleation. The larger the volume of water contained, the higher the nucleation temperature. Besides, an increase of the cooling rate of water makes the blockage extent of dendritic ice growth decreased under the same inside diameter. The water inside the smaller cylinder is more likely to be blocked by dendritic ice than that of the larger one for the same cooling rate. The addition of nucleation agents into water containers can effectively improve the nucleation probability, and thus increase the coefficient of perfcrmance of cool storage air-conditioning system.

Acknowledgement-The authors gratefully acknowledge the support of the National Science Council, ROC, for this work through Grant No. NSC 86-2212-E-002-065.

\section{REFERENCES}

1. Gilpin, R. R., Cooling of a horizontal cylinder of water through its maximum density point at $4^{\circ} \mathrm{C}$. International Journal of Heat and Mass Transfer, 1975, 18, 1307-1315.
2. Gilpin, R. R., The effect of cooling rate on the formation of dendritic ice in a pipe with no main flow. Journal of Heat Transfer, 1977, 99, 419-424.

3. Chen, K. C., Takeuchi, M. and Gilpin, R. R., Transient natural convection in horizontal water pipes with maximum density effect and supercooling. Numerical Heat Transfer, 1978, 1, 101-115.

4. Kashiwagi, T., Itoh, S., Kurosaki, Y. and Hirose, S., Effects of the natural convection in a partially supercooled water cell on the release of supercooling. ASHRAE Transactions, 1987, 93, 49-61.

5. Saito, A., Utaka, Y., Okawa, S., Matsuzawa, K. and Tamaki, A., Fundamental research on the supercooling phenomenon on heat transfer surfaces-investigation of an effect of characteristics of surface and cooling rate on a freezing temperature of supercooled water. International Journal of Heat and Mass Transfer, 1990, 33(8), $1697-$ 1709.

6. Saito, A. and Okawa, S., Fundamental research on initiation of freezing of supercooled water on heat transfer surface. Proceedings of the 10th International Heat Transfer Conference, Brighton, UK, Vol. 7, 1994, pp. 121-126.

7. Arnold, D., Laboratory performance of an encapsulatedice store. ASHRAE Transactions, 1991, 97(2), 1170-1178.

8. Moffat, R. J. Using uncertainty analysis in the planning of an experiment. Journal of Fluids Engineering, 1985, 107, 173-182.

9. Vonnegut, B., Nucleation of ice formation by silver iodide. Journal of Applied Physics, 1947, 18, 593-595. 